ROYAL SOCIETY OF CHEMISTRY

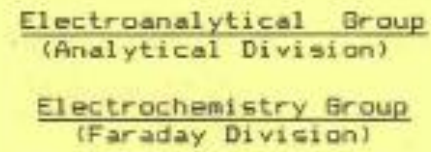

INTERNATIONAL SVMPOSIUM ON

ELECTROANALYSIS IN EIOCHEMICAL. ENUIRONMENTAL. AND INDUSTRIAL SCIENCES:

Loughbaraugh University of Technology, Loughboraugh, Leicestershire, UK.

Tuesday 11 - Friday 14th APRIL 1989.

PFOGRAMME AND AESTRACTS OF PAFEFB 


\title{
Cathodic stripping voltammetry of pyridine-2-thiol and some related compounds
}

\author{
José María Fernández Álvarez and Malcolm R. Smyth \\ School of Chemical Sciences, Dublin City University, Glasnevin, Dublin 9, Ireland
}

The cathodic stripping voltammetric behaviour of pyridine-2-thiol and some related heterocyclic thiols has been studied at a static mercury drop electrode. The influence of substituents on the adsorption of these compounds on the mercury electrode, and the nature of the different thiolates responsible for the subsequent stripping signals have been investigated. Differential-pulse cathodic stripping voltammetry was used to establish linear calibration ranges for the compounds studied. The use of a preconcentration time of $240 \mathrm{~s}$ in open circuit allowed a detection limit of $8.0 \times 10^{-9} \mathrm{M}$ to be attained for pyridine-2-thiol.

Thiols are of great interest in the fields of biochemistry, pharmacology and industry, and numerous methods are available for their determination. The polarographic behaviour of thiols is generally believed to be due to the oxidation of mercury in the presence of the thiol. The chemical reaction between the oxidised mercury and the thiol results in the formation of a mercury salt, which is adsorbed at the surface of the electrode, as demonstrated by electrocapillary curve measurements. Cathodic stripping voltammetry (CSV) possesses a high sensitivity for the determination of thiols as the reduction signal proceeds from the adsorbed thiolate film on the surface of the electrode. Other compounds such as thioamides react with mercury to form mercury(1) sulphide, and can be determined indirectly via the sulphide stripping wave. In this contribution the CSV behaviour of pyridine-2-thiol, pyrimidine-2-thiol , 4methylpyrimidine-2-thiol hydrochloride , 2-mercaptopyridine $\mathrm{N}$-oxide and 2mercaptopyridin-3-ol has been studied. All four compounds gave rise to single well defined oxidation waves whose diffusion currents remained virtually unaltered over the $\mathrm{pH}$ range studied. These reactions were shown to be quasi-reversible in nature, and some adsorption phenomena were observed. The adsorption of these molecules at the surface of the electrode has now been studied further. A pre-concentration step carried out under electrolysis or in open-circuit conditions yields different adsorbed thiolates. The nature of these films is discussed, and differential-pulse cathodic stripping voltammetry (DPCSV) has been shown to be a useful electroanalytical technique for the determination of these thiols. 